\title{
'||-|||||||||||||||||||||||||||||||||||||||||||||||||||||||||||||||||||||.
}

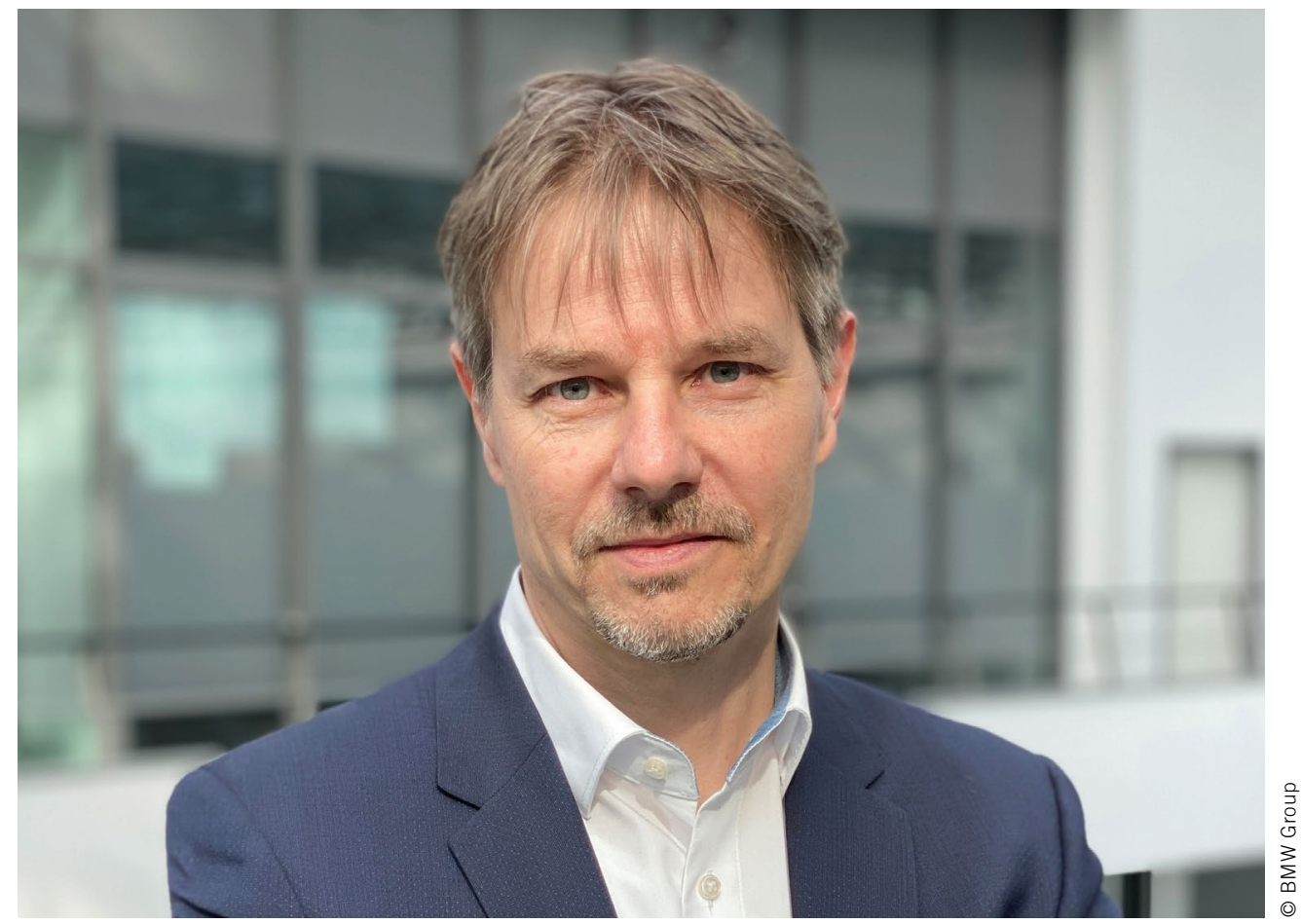

Kai Lars Barbehön Vice President for Central Control Systems, Physical Vehicle Electrical System and Energy Supply at BMW in Munich (Germany)

\section{Just Being Good Will Not Be Good Enough!}

It is not really new that the automotive sector is in the throes of change. The debate is, at the most, about which trend is currently the strongest driver of change; is it electrification, automation, or connectivity. From whichever perspective we choose to view the situation, the common theme is that the rate of change poses a considerable challenge to us as the designers of automotive electronics. The newcomers to the automotive business seem to handle these challenges much better than the automotive manufacturers who have shaped mobility over the past 10 years. To make sure they do not fall behind, a new understanding is required of what makes mobility desirable both today and in the future. The previously appreciated values for automotive electronics such as robustness and quality need to be supplemented with new attributes such "always fresh" and the ability to be updated.

Experiences from the world of Consumer Electronics (CE) form the reference: It is not just about regular cycles of software updates over-the-air, but about the vehicle being embedded in the customer's digital ecosystem as a "best-managed device." Seamless services, personalization and intelligent assistants are very high up on the wish list. However, today's E/E architectures, development processes and support organizations are no longer able to design solutions to fulfill these requirements. Contemporary dominant domain-oriented $\mathrm{E} / \mathrm{E}$ approaches no longer result in manageable, functional effect chains. Fine levels of granularity in architectural scaling, mainly as a result of the paradigm of an E/E configuration optimized from a production cost point of view at the time of sale, lead to customer-specific vehicle electrical systems with kilometers of cabling including thousands of individual modules. The limits of manufacturability have now been reached. And yet approaches describing solutions to this already exist: high integration of today's still distributed domain controllers into high performance integration platforms with computing power that we only know from the CE world; zonal, physical $\mathrm{E} / \mathrm{E}$ architectures with automatically manufactured stepped cable sets in dedicated areas contacted to so-called zone modules; intelligent energy networks with functionally switchable threads using e-fuses that lay claim to highly energy-efficient energy management and safe energy supply. However, this change of direction requires a paradigm shift in the organization and approaches to business management control because the new approaches reach the limits of management by reporting category. High levels of integration and hence hardware units, software updates and the ability to book services open up digital post-sale opportunities that must be included in any economic feasibility studies.

As a new member of ATZelectronic's advisory board, I am very much looking forward to accompanying you along the exciting path toward change in the automotive electronic world. 